\title{
A single day of mixed-macronutrient overfeeding does not elicit compensatory appetite or energy intake responses but exaggerates postprandial lipaemia during the next day in healthy young men
}

\author{
Kevin Deighton $^{1 *}$, Andy J. King ${ }^{1}$, Jamie Matu ${ }^{1,2}$, Oliver M. Shannon ${ }^{1,3}$, Oliver Whiteman ${ }^{1}$, Alice Long ${ }^{1}$, \\ Matthew D. Huby ${ }^{1}$, Miroslav Sekula ${ }^{1}$ and Adrian Holliday ${ }^{1}$ \\ ${ }^{1}$ Institute for Sport, Physical Activity E Leisure, Leeds Beckett University, Leeds LS6 3QS, UK \\ ${ }^{2}$ Leeds Institute of Rheumatic and Musculoskeletal Medicine, University of Leeds, Leeds LS7 4SA, UK \\ ${ }^{3}$ Human Nutrition Research Centre, Institute of Cellular Medicine, Newcastle University, Newcastle upon Tyne NE2 4HH, UK \\ (Submitted 13 September 2018 - Final revision received 11 January 2019 - Accepted 21 January 2019 - First published online 30 January 2019)
}

\section{Abstract}

Discrete episodes of overconsumption may induce a positive energy balance and impair metabolic control. However, the effects of an ecologically relevant, single day of balanced macronutrient overfeeding are unknown. Twelve healthy men (of age 22 (SD 2 ) years, BMI $26 \cdot 1$ (sD 4.2$) \mathrm{kg} / \mathrm{m}^{2}$ ) completed two $28 \mathrm{~h}$, single-blind experimental trials. In a counterbalanced repeated measures design, participants either consumed their calculated daily energy requirements (energy balance trial (EB): 10755 (sD 593) kJ) or were overfed by $50 \%$ (overfeed trial (OF): 16132 (sD 889) kJ) under laboratory supervision. Participants returned to the laboratory the next day, after an overnight fast, to complete a mixed-meal tolerance test (MTT). Appetite was not different between trials during day $1(P>0 \cdot 211)$ or during the MTT in the fasted or postprandial state $(P>0.507)$. Accordingly, plasma acylated ghrelin, total glucagon-like peptide-1 and total peptide YY concentrations did not differ between trials during the MTT (all $P>0.335$ ). Ad libitum energy intake, assessed upon completion of the MTT, did not differ between trials (EB 6081 (sD 2260) kJ; OF 6182 (sD 1960) kJ; $P=0.781$ ). Plasma glucose and insulin concentrations were not different between trials $(P>0.715)$. Fasted NEFA concentrations were lower in OF compared with EB $(P=0.005)$, and TAG concentrations increased to a greater extent on OF than on EB during the MTT $(P=0 \cdot 009)$. The absence of compensatory changes in appetite-related variables after $1 \mathrm{~d}$ of mixed macronutrient overfeeding highlights the limited physiological response to defend against excess energy intake. This supports the concept that repeated discrete episodes of overconsumption may promote weight gain, while elevations in postprandial lipaemia may increase CVD risk.

\section{Key words: Gut hormones: Compensation: Postprandial metabolism: Appetite regulation}

The increased prevalence of overweight and obesity represents a worldwide public health challenge ${ }^{(1)}$ and is the result of a chronic positive energy balance achieved via a long-term surplus of energy intake over energy expenditure ${ }^{(2)}$. Although long-term weight loss is achievable with lifestyle modification $^{(3)}$, this is notoriously difficult due to the stimulation of physiological adaptations to weight loss that favour weight regain ${ }^{(4)}$. Considering the challenges of weight loss, it remains essential to better understand the factors that may cause initial weight gain to provide guidance for prevention.

Current evidence suggests that increases in BMI during adulthood $^{(5)}$ are the result of discrete periods of overconsumption, rather than smaller daily energy imbalances ${ }^{(6-9)}$. Indeed, repeated episodes of overconsumption during weekends and public holidays may be sufficient to account for longterm weight gain ${ }^{(6,8)}$. To date, experimental investigations into the compensatory responses to overfeeding have primarily focused on changes in circulating appetite-related hormone concentrations; with mixed findings likely due to differences in the duration, magnitude and composition of the dietary interventions $^{(10-15)}$. Although episodes of overconsumption often occur on only $1 \mathrm{~d} /$ week and with a balanced macronutrient profile ${ }^{(8)}$, there has been little investigation into the compensatory responses to this model of overconsumption. In addition, an integrated assessment of appetite perceptions and subsequent energy intake alongside mechanistic variables (i.e. appetite-related hormones) is essential to fully understand the magnitude of compensatory responses.

Discrete periods of overconsumption may also impair metabolic control. In this regard, overfeeding with a high-fat diet ( $\geq 50 \%$ increase in energy; $\geq 60 \%$ fat content) has consistently been shown to impair insulin sensitivity in humans ${ }^{(10,14,16-18)}$.

Abbreviations: EB, energy balance; GLP-1, glucagon-like peptide-1; MTT, mixed-meal tolerance test; OF, overfeed; PYY, peptide YY. 
A recent study by Lundsgaard et $a l .{ }^{(18)}$ has further advanced these findings by demonstrating opposing regulatory effects of high-carbohydrate $v$. high-fat overfeeding on central and peripheral insulin sensitivity. In this landmark study, $3 \mathrm{~d}$ of overfeeding with a high-fat diet (+75\% kJ, 78\% fat) improved hepatic glucoregulation but impaired muscle insulin sensitivity, whereas overfeeding with a high-carbohydrate diet (+75\% kJ, $80 \%$ carbohydrate) induced hepatic insulin resistance but increased insulin sensitivity in the muscle. This evidence suggests that divergent macronutrient intake may mediate the impaired metabolic control observed during overfeeding, and it remains unclear whether short-term overfeeding with a balanced macronutrient profile would provide sufficient stimulus to induce metabolic impairments.

The primary purpose of this study was to determine whether $1 \mathrm{~d}$ of overfeeding with a balanced macronutrient profile induces compensatory changes in appetite perceptions, appetite-related hormone concentrations and energy intake during a mixed-meal tolerance test (MTT) the next day. The effects of overfeeding on fasted and postprandial markers of metabolic control during the MTT were also assessed. Participants were blinded to the overfeeding intervention to assess the physiological compensatory responses to overfeeding, while minimising the influence of psychological factors and participant bias. These findings contribute to understanding the consequences of common dietary practices and mechanisms of weight control.

\section{Methods}

\section{Participants}

This study was conducted according to the guidelines laid down in the Declaration of Helsinki, and all procedures were approved by the Ethics Advisory Committee at Leeds Beckett University. Twelve healthy men were recruited for the study and written informed consent was obtained from all participants. Participants were non-smokers, not taking medication, weight stable for at least 6 months before the study and were not dieting. The physical characteristics of participants are as follows: age 22 (SD 2) years, body mass $82 \cdot 4$ (SD 10.2) $\mathrm{kg}, \mathrm{BMI}$ $26 \cdot 1$ (SD $4 \cdot 2) \mathrm{kg} / \mathrm{m}^{2}$, waist circumference $86 \cdot 2(8 \cdot 4) \mathrm{cm}$. This trial is registered at ClinicalTrials.gov (ID: NCT03301948).

\section{Experimental protocol}

Overview. Each participant completed a screening session and two $28 \mathrm{~h}$ experimental trials separated by 1 week in a singleblind counterbalanced crossover design. The initial screening session involved the collection of anthropometric measures, health screening and confirmation of the acceptability of the foods to be provided during the study.

Standardisation. Participants completed a food diary detailing all foods and drinks consumed in the $24 \mathrm{~h}$ before their first experimental trial and repeated this before their second trial. Alcohol, caffeine and strenuous physical activity were not permitted during this period. All trials commenced between
08.00 and 09.00 hours after an overnight fast of at least $10 \mathrm{~h}$, and participants exerted themselves minimally when travelling to the laboratory. Verbal confirmation of adherence to these standardisation procedures was obtained at the beginning of each experimental trial.

Day 1. On day 1 of each trial, participants visited the laboratory to consume breakfast (08.00-09.00 hours), lunch (12.0013.00 hours) and an evening meal (17.00-18.00 hours). All meals were prepared by the research team, consumed in isolation and consumed at the same time of day in both trials. In one trial these meals provided the calculated energy requirements for each individual (energy balance (EB) trial). In the other trial, the meals were covertly manipulated to increase the energy content by $50 \%$ (overfeed (OF) trial). Participants were required to consume all of the foodstuffs provided at each meal and this was confirmed by a member of the research team. The magnitude of overfeeding $(+50 \% \mathrm{~kJ})$ was selected to align with previous research that investigated the appetite-related and metabolic responses over more prolonged periods of $5-7 \mathrm{~d}^{(10,14,16)}$. The impairments in metabolic control observed during these studies suggest that overfeeding by $50 \%$ provides a significant metabolic challenge, while we also deemed this to be a realistic target to enable covert dietary manipulation and participant blinding to the intervention.

Participants were permitted to leave the laboratory between meals but were required to remain on the university campus to minimise physical activity. Each participant was fitted with a SenseWear Pro3 Armband (BodyMedia) upon arrival at the laboratory on day 1 of each trial, and these were worn until arrival at the laboratory for day 2 of the respective trial. This was intended to discourage physical activity and was used to check that the energy expenditure of participants was matched between trials ${ }^{(19)}$. Participants returned home after consumption of the evening meal and came back to the laboratory the next morning having fasted overnight. Verbal confirmation of adherence to the overnight fast was obtained at the beginning of the second day of each trial for all participants.

Day 2. On day 2 of each trial, participants arrived at the laboratory between 08.00 and 09.00 hours to complete an MTT. Upon arrival, participants rested in a semi-supine position for 5 min before a cannula (Introcan Safety; B Braun) was inserted into an antecubital vein. A baseline blood sample and appetite visual analogue scale were collected approximately $10 \mathrm{~min}$ after the insertion of the cannula before the participant commenced the MTT.

The MTT involved consumption of white bread (toasted), butter, strawberry jam and orange juice. The energy content of the meal was relative to each participant's estimated energy requirements by providing the same energy content as the porridge breakfast meal on day 1 of the EB trial (2748 (SD 198) kJ). This approach was used to standardise energy intake for differences in body mass/composition between participants $^{(20)}$. The macronutrient composition of the MTT meal included $60 \%$ carbohydrate, $32 \%$ fat and $8 \%$ protein, to increase ecological validity and provide a more 'physiological response' compared with glucose- or fat-only challenges ${ }^{(20,21)}$. 
Blood samples and appetite perceptions were collected every 30 min during the $180 \mathrm{~min}$ postprandial period, while participants rested within the laboratory (sitting, reading or listening to music). Upon completion of the postprandial period, participants were provided with an ad libitum pasta meal to assess energy intake. Water intake was measured during the first trial for each participant and replicated during the second trial (505 (sD 288) $\mathrm{ml}$ ).

\section{Overfeeding intervention}

The meals consumed during day 1 of EB provided the estimated daily energy needs for each participant, which were calculated using the Mifflin-St Jeor equation ${ }^{(22)}$ and a physical activity factor of 1.4 to represent the sedentary nature of experimental testing days. This approach to estimate energy requirements is consistent with previous literature ${ }^{(10,14,17,23)}$ and was deemed preferable to designing the intervention based on self-report food diaries due to the established concerns over the accuracy of self-report measures ${ }^{(24)}$. The energy content of all meals comprised $50 \%$ carbohydrate, $35 \%$ fat and $15 \%$ protein, which is in accordance with the UK dietary guidelines ${ }^{(25)}$. During day 1 of OF, the raw weight of foodstuffs included in the meals was increased by $50 \%$.

The manipulation of food weights was covertly achieved by adjusting the water content of meals, cooking duration, and through the addition of thickening agents to the meals provided during EB. To avoid any a priori awareness of the participants to the overfeeding intervention, this experiment was described as involving 'nutrient manipulation' during recruitment and throughout the study. The blinding of participants to the true aims of the study was deemed important to assess the physiological compensatory responses to overfeeding, while minimising the influence of psychological factors and participant bias. All participants completed a blinding assessment upon completion of the experiment and the true nature of the intervention was discussed. The meals provided were as follows: porridge (breakfast), pasta dish and soup (lunch) and rice dish (evening meal). A milkshake was provided alongside each meal which contained $837 \mathrm{~kJ}$ on EB and $1255 \mathrm{~kJ}$ on OF for all participants. The remaining energy intake was divided evenly across the three meals. The meal ingredients, preparation methods and quantities for an example participant are provided in Table 1.

\section{Appetite, palatability and energy intake assessment}

Appetite perceptions (hunger, satisfaction, fullness and prospective food consumption) were assessed using $100 \mathrm{~mm}$ visual analogue scales with descriptors anchored at each end describing the extremes (e.g. 'I am not hungry at all'/I have never been more hungry') ${ }^{(26)}$. These measures were collected before and after each meal on day 1 , and in the fasted state and every $30 \mathrm{~min}$ during the MTT. A composite appetite score was calculated for each time point as the mean value of the four appetite perceptions after inverting the values for satisfaction and fullness ${ }^{(27)}$. Palatability ratings (visual appeal, smell, taste, aftertaste and pleasantness) were obtained for all meals immediately after consumption ${ }^{(26)}$. A composite palatability score was calculated as the mean value of the palatability subscales.

Upon completion of the 180 min postprandial period, an ad libitum meal was provided, consisting of penne pasta, cheddar cheese, tomato sauce and olive oil in accordance with previous research ${ }^{(28)}$. Pasta was cooked in a microwave for $13 \mathrm{~min}$ in unsalted water at $700 \mathrm{~W}$ before being mixed with the remaining ingredients and re-heated for $2 \mathrm{~min}$ at $700 \mathrm{~W}$. The macronutrient content of the meal was $50 \%$ carbohydrate, $35 \%$ fat and $15 \%$ protein $^{(25)}$. Participants consumed the ad libitum meal in isolation to prevent any social influences affecting food intake. Participants were provided with a bowl of the pasta meal, which was replaced by an investigator before the participant had emptied it and with minimal interaction. No time limit was set for eating, and participants were instructed to eat until 'comfortably full'. Food intake was determined as the weighted difference in food before and after eating.

\section{Blood sampling and biochemical analyses}

At each time point, venous blood samples were collected into one 5-ml and one 9-ml pre-cooled EDTA monovette (Sarstedt). The $9 \mathrm{ml}$ monovettes were used for the determination of plasma concentrations of glucose, insulin, TAG, NEFA, total glucagon-like peptide-1 (GLP-1) and total peptide YY (PYY). The 5-ml monovettes were used for the determination of plasma acylated ghrelin concentrations and were pre-treated on the morning of testing, to prevent the degradation of acylated ghrelin, with a 50- $\mu$ l solution of PBS, $p$-hydroxymercuribenzoic acid and sodium hydroxide. Both monovettes were spun at $1500 \mathrm{~g}$ for $10 \mathrm{~min}$ at $4^{\circ} \mathrm{C}$. Plasma from the $9 \mathrm{ml}$ tube was immediately aliquoted into $2-\mathrm{ml}$ Eppendorf tubes before storage at $-20^{\circ} \mathrm{C}$, whereas $1 \mathrm{ml}$ of plasma from the $5-\mathrm{ml}$ monovette was mixed with $100 \mu \mathrm{l}$ of $1 \mathrm{M}$ hydrochloric acid ${ }^{(29)}$ before storage at $-20^{\circ} \mathrm{C}$.

Plasma glucose, TAG and NEFA concentrations were analysed from all blood samples photometrically with reagents from Instrumentation Laboratory and Wako Chemicals, respectively. Insulin was analysed from all blood samples using a commercially available enzyme immunoassay (IBL). Plasma acylated ghrelin, total GLP-1 and total PYY concentrations were analysed using commercially available enzyme immunoassays (SPI BIO; EMD Millipore). Due to the plate layout of the acylated ghrelin, total GLP-1 and total PYY ELISA, these analytes were measured at all time points except for $150 \mathrm{~min}$. To eliminate inter-assay variation, samples from each participant were analysed in the same run. The within-batch CV were as follows: acylated ghrelin 3.3\%, total GLP-1 3.0\%, total PYY 5.1\%, glucose $3.2 \%$, insulin $4.3 \%$, TAG $3.7 \%$ and NEFA $2.8 \%$.

\section{Statistical analyses}

Data were analysed using IBM SPSS version 24 for Windows. Sphericity of the data was assessed using Mauchly's test of sphericity, with any violation corrected using the GreenhouseGeisser method. Fasted measures and ad libitum energy intake were compared using paired $t$ tests. The dynamic appetite, 
Table 1. Ingredients, preparation methods and example quantities for the meals provided during day 1 of the energy balance (EB) and overfeed (OF) trials

\begin{tabular}{|c|c|c|c|}
\hline & Energy balance & Overfeed & Preparation methods \\
\hline Milkshake & $837 \mathrm{~kJ}$ & $1255 \mathrm{~kJ}$ & \multirow{8}{*}{$\begin{array}{l}\text { Guar gum mixed with water (EB). All ingredients } \\
\text { combined and shaken to mix }\end{array}$} \\
\hline Whole milk & $179.4 \mathrm{ml}$ & $269 \cdot 2 \mathrm{ml}$ & \\
\hline Single cream & $3.6 \mathrm{ml}$ & $5.4 \mathrm{ml}$ & \\
\hline Maltodextrin & $17.9 \mathrm{~g}$ & $26.9 \mathrm{~g}$ & \\
\hline Whey protein isolate & $1.3 \mathrm{~g}$ & $2.0 \mathrm{~g}$ & \\
\hline Vanilla flavouring & Five drops & Five drops & \\
\hline Guar gum & $1.3 \mathrm{~g}$ & $N / A$ & \\
\hline Water & $100 \mathrm{ml}$ & $N / A$ & \\
\hline Breakfast & $2571 \mathrm{~kJ}$ & $3857 \mathrm{~kJ}$ & \multirow{8}{*}{$\begin{array}{l}\text { Porridge cooked in a microwave at } 700 \mathrm{~W} \text { for } 3 \mathrm{~min} \\
\text { (EB) or } 2 \mathrm{~min}(\mathrm{OF}) \text { after combining all ingredients }\end{array}$} \\
\hline Porridge oats & $57.6 \mathrm{~g}$ & $86.4 \mathrm{~g}$ & \\
\hline Whole milk & $111.4 \mathrm{ml}$ & $167.1 \mathrm{ml}$ & \\
\hline Single cream & $61.5 \mathrm{ml}$ & $92.2 \mathrm{ml}$ & \\
\hline Double cream & $12.5 \mathrm{ml}$ & $18.7 \mathrm{ml}$ & \\
\hline Maltodextrin & $28.8 \mathrm{~g}$ & $43 \cdot 2 \mathrm{~g}$ & \\
\hline Whey protein isolate & $11.5 \mathrm{~g}$ & $17.3 \mathrm{~g}$ & \\
\hline Water & $141.6 \mathrm{ml}$ & $\mathrm{N} / \mathrm{A}$ & \\
\hline Lunch & $2571 \mathrm{~kJ}$ & $3857 \mathrm{~kJ}$ & \multirow{7}{*}{$\begin{array}{l}\text { Pasta cooked in a microwave at } 700 \mathrm{~W} \text { for } 15 \mathrm{~min}(\mathrm{~EB}) \\
\text { or } 7.5 \mathrm{~min}(\mathrm{OF}) \text { before combining with the remaining } \\
\text { ingredients }\end{array}$} \\
\hline Pasta dish & $1286 \mathrm{~kJ}$ & $1929 \mathrm{~kJ}$ & \\
\hline White spaghetti & $51.8 \mathrm{~g}$ & $77.7 \mathrm{~g}$ & \\
\hline Green pesto & $21.6 \mathrm{~g}$ & $32.4 \mathrm{~g}$ & \\
\hline Butter & $4.3 \mathrm{~g}$ & $6.5 \mathrm{~g}$ & \\
\hline Whey protein isolate & $4.3 \mathrm{~g}$ & $6.5 \mathrm{~g}$ & \\
\hline Water & $362.6 \mathrm{ml}$ & $233.1 \mathrm{ml}$ & \\
\hline Soup & $1286 \mathrm{~kJ}$ & $1929 \mathrm{~kJ}$ & \multirow{10}{*}{$\begin{array}{l}\text { Guar gum mixed with the water (EB). Soup cooked in a } \\
\text { microwave for } 2 \text { min at } 700 \mathrm{~W} \text { after combining all } \\
\text { ingredients }\end{array}$} \\
\hline Tomato soup & $126.9 \mathrm{~g}$ & $190 \cdot 3 \mathrm{~g}$ & \\
\hline Single cream & $49.3 \mathrm{~g}$ & $74.0 \mathrm{~g}$ & \\
\hline Yogurt & $84.6 \mathrm{~g}$ & $126.9 \mathrm{~g}$ & \\
\hline Maltodextrin* & $23.1 \mathrm{~g}$ & $38.1 \mathrm{~g}$ & \\
\hline Vegetable stock cube & One cube & One cube & \\
\hline Tomato ketchup ${ }^{*}$ & $10 \mathrm{~g}$ & $\mathrm{~N} / \mathrm{A}$ & \\
\hline Guar gum & $2.3 \mathrm{~g}$ & N/A & \\
\hline Water & $143.1 \mathrm{~g}$ & N/A & \\
\hline Evening meal & $2571 \mathrm{~kJ}$ & $3857 \mathrm{~kJ}$ & \\
\hline White rice & $79.8 \mathrm{~g}$ & $119 \cdot 7 \mathrm{~g}$ & \multirow{6}{*}{$\begin{array}{l}\text { Rice cooked in a microwave at } 700 \mathrm{~W} \text { for } 15 \mathrm{~min}(\mathrm{~EB}) \text { or } \\
7.5 \mathrm{~min}(\mathrm{OF}) \text { before combining with the remaining } \\
\text { ingredients }\end{array}$} \\
\hline Butter & $26.6 \mathrm{~g}$ & $39.9 \mathrm{~g}$ & \\
\hline Chicken slices & $46.5 \mathrm{~g}$ & $69.8 \mathrm{~g}$ & \\
\hline Barbecue sauce & $33.2 \mathrm{~g}$ & $49.9 \mathrm{~g}$ & \\
\hline Whey protein isolate & $6.6 \mathrm{~g}$ & $10.0 \mathrm{~g}$ & \\
\hline Water & $415.0 \mathrm{ml}$ & $398.6 \mathrm{ml}$ & \\
\hline
\end{tabular}

* Note that a small proportion of maltodextrin was replaced with tomato ketchup in the EB trial when preparing the soup dish. This was deemed necessary to ensure blinding of the meals and this did not alter the macronutrient composition of the meal. The energy content of all meals comprised $50 \%$ carbohydrate, $35 \%$ fat and $15 \%$ protein. Differences in preparation methods are denoted as the EB trial and OF trial to describe the specific procedures for each trial.

hormonal and metabolic responses to the MTT were compared using a two-way (trial $\times$ time) repeated-measures ANOVA. Significant interaction effects were explored using unadjusted paired $t$ tests. Statistical significance was accepted at $P<0 \cdot 05$. Effect sizes are presented as Cohen's $d$ and interpreted as $<0 \cdot 2$ trivial, $\geq 0 \cdot 2$ small, $\geq 0 \cdot 6$ moderate, $\geq 1 \cdot 2$ large, $\geq 2$ very large and $\geq 4$ extremely large.

Results in text and tables are presented as means and standard deviations. Graphical representations of results are presented as means and standard errors of the mean. Appetite, hormonal and metabolic responses to the MTT are presented as line graphs to display changes over time. Time-averaged AUC values were calculated for these variables using the trapezoidal method, which are displayed in figures alongside the individual participant responses in the online Supplementary material to allow further examination of the findings.

Based on previous data from our laboratory ${ }^{(28)}$, a sample size of twelve participants provided $>80 \%$ power to detect a $1250 \mathrm{~kJ}$ compensatory increase in energy intake at the ad libitum meal.
This calculation was performed using G*Power with an $\alpha$ value of $5 \%{ }^{(30)}$.

\section{Results}

Day 1

Energy intake was 10755 (SD 593) and 16132 (sD 889) kJ on the $\mathrm{EB}$ and $\mathrm{OF}$ trials, respectively. Estimated energy expenditure was 12423 (SD 1340) and 12450 (sD 1679) kJ on day 1 of the EB and OF trials, respectively $(P=0.917)$.

Appetite was not different between trials during day 1 (online Supplementary Fig. S1; main effect of trial $P=0 \cdot 212$, trial $\times$ time interaction $P=0.783$ ). Palatability of the meals provided on day 1 was not significantly different between trials, except for the milkshake consumed as part of the evening meal which was significantly more palatable on OF compared with EB $(P=0.020$; online Supplementary Table S1). Water intake was 
not different between trials (EB 2003 (sD 848) ml; OF 1876 (sD 842) $\mathrm{ml} ; P=0.674$ ).

\section{Day 2}

Fasted measures of appetite, plasma appetite-related hormone, glucose, insulin and TAG concentrations did not differ between trials (all $P>0 \cdot 188$ ). Fasted NEFA concentrations were significantly higher in EB than in $\mathrm{OF}(P=0.005$; Table 2$)$.

Appetite changed over time $(P<0.0005)$ in response to the MTT but without any differences in the magnitude or time course of these responses between trials (main effect of trial $P=0.720$, trial $\times$ time interaction $P=0 \cdot 706$; Fig. 1(a)). Ad libitum energy intake upon completion of the MTT was not different between trials $(P=0.781 ; d=0.05$; Fig. 1(b)). Palatability of the MTT meal was not different between trials (EB 72 (SD 9); OF 72 (SD 10); $P=0.885 ; d=0.03$ ). Palatability of the ad libitum pasta meal was not different between trials (EB 69 (SD 12); OF 70 (sD 11); $P=0 \cdot 656 ; d=0 \cdot 09$ ).

Plasma concentrations of appetite-related hormones changed over time (all $P \leq 0.021$ ) in response to the MTT but without any difference in the magnitude or time course of these responses between trials (main effect of trial, all $P \geq 0.336$; trial $\times$ time interaction, all $P \geq 0.364$; Fig. 2).

Plasma concentrations of glucose, insulin, TAG and NEFA changed over time in response to the MTT (all $P<0.0005)$ (Fig. 3). There were no differences in the magnitude or time course of these responses between trials for glucose and insulin concentrations (main effect of trial, both $P \geq 0.929$; trial $\times$ time interaction, both $P \geq 0 \cdot 716$ ). Alternatively, plasma TAG concentrations diverged between trials as the duration of the postprandial period increased, resulting in a significant trial $\times$ time interaction effect $(P=0.009)$ but no main effect of trial $(P=0 \cdot 219)$. A significant trial $\times$ time interaction effect was also detected for plasma NEFA $(P=0 \cdot 001)$ due to higher concentrations in $\mathrm{EB}$ than in $\mathrm{OF}$ in the fasted baseline state. In accordance with other plasma metabolites, there was no main effect of trial for plasma NEFA concentrations $(P=0 \cdot 113)$

AUC data and individual participant responses during the MTT are presented in the online Supplementary materials. There were no significant differences between trials in the AUC values for appetite, appetite-related hormone concentrations or plasma metabolites (all $P \geq 0 \cdot 175, d \leq 0 \cdot 45$ ).

\section{Blinding assessment}

In response to the exit questionnaire, eight out of the twelve participants stated that they noticed a difference between meals during day 1 of EB and OF. Of these eight participants, only one successfully guessed that the meals differed in energy content. The remaining participants guessed that the aim of the intervention was to manipulate the sweetness of meals (two participants), the sweetness and thickness of meals
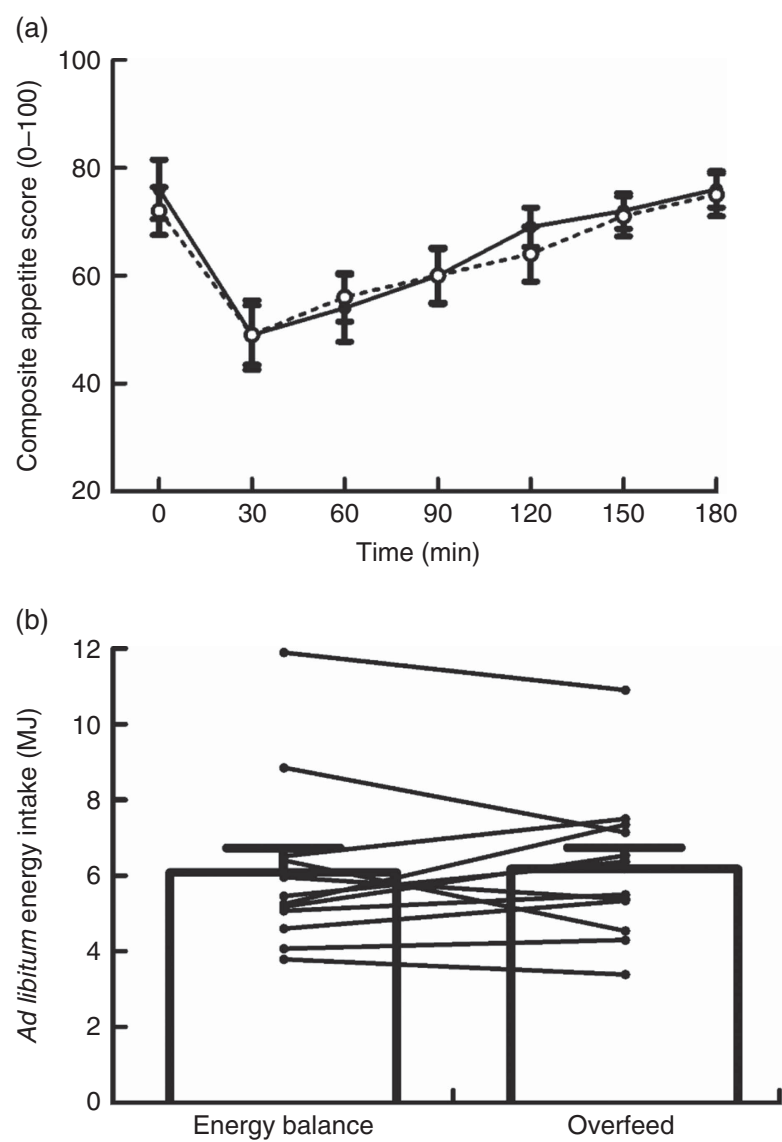

Fig. 1. Composite appetite score (a) and ad libitum energy intake (b) during a mixed-meal tolerance test after a day of supervised feeding in accordance with estimated energy requirements (energy balance trial; 0 ; solid line) or $50 \%$ overfeeding (overfeed trial; $O$; dashed line). Values are means ( $n 12)$, with standard errors of the mean represented by vertical bars. Lines in (b) represent individual participants.

Table 2. Fasted appetite perceptions, plasma appetite-related hormone concentrations and metabolite concentrations after a day of supervised feeding in accordance with estimated energy requirements (energy balance trial) or $50 \%$ overfeeding (overfeed trial)

(Mean values and standard deviations, $n$ 12)

\begin{tabular}{|c|c|c|c|c|c|c|}
\hline & \multicolumn{2}{|c|}{ Energy balance } & \multicolumn{2}{|c|}{ Overfeed } & \multirow[b]{2}{*}{$P$} & \multirow[b]{2}{*}{$d$} \\
\hline & Mean & SD & Mean & SD & & \\
\hline Composite appetite score $(0-100)$ & 76 & 19 & 72 & 15 & 0.508 & 0.19 \\
\hline Plasma acylated ghrelin (pg/ml) & 179.8 & $351 \cdot 3$ & 188.9 & 364.4 & $0 \cdot 189$ & 0.03 \\
\hline Plasma GLP-1 (рм) & $50 \cdot 4$ & $20 \cdot 7$ & 47.4 & $15 \cdot 4$ & 0.405 & 0.17 \\
\hline Plasma PYY (pg/ml) & $99 \cdot 0$ & $49 \cdot 1$ & $105 \cdot 4$ & $71 \cdot 6$ & 0.602 & 0.11 \\
\hline Plasma glucose $(\mathrm{mmol} / \mathrm{l})$ & 4.8 & 0.5 & 4.9 & 0.4 & 0.347 & 0.31 \\
\hline Plasma insulin (pmol/l) & 187.6 & $82 \cdot 6$ & $197 \cdot 1$ & $86 \cdot 2$ & 0.442 & 0.11 \\
\hline Plasma TAG $(\mathrm{mmol} / \mathrm{l})$ & 0.98 & 0.32 & 0.98 & 0.21 & 0.940 & 0.02 \\
\hline Plasma NEFA (mmol/l) & 0.49 & 0.12 & 0.37 & 0.14 & 0.005 & 0.90 \\
\hline
\end{tabular}

GLP-1, glucagon-like peptide-1; PYY, peptide YY. 
(a)

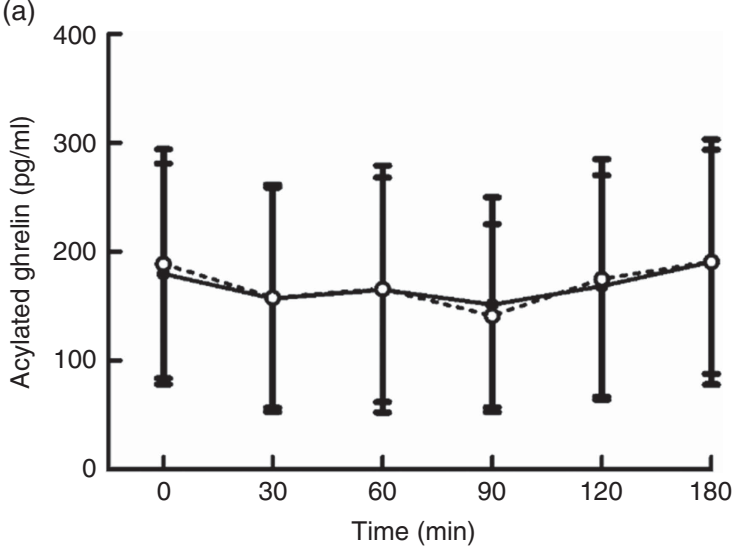

(b)



(c)

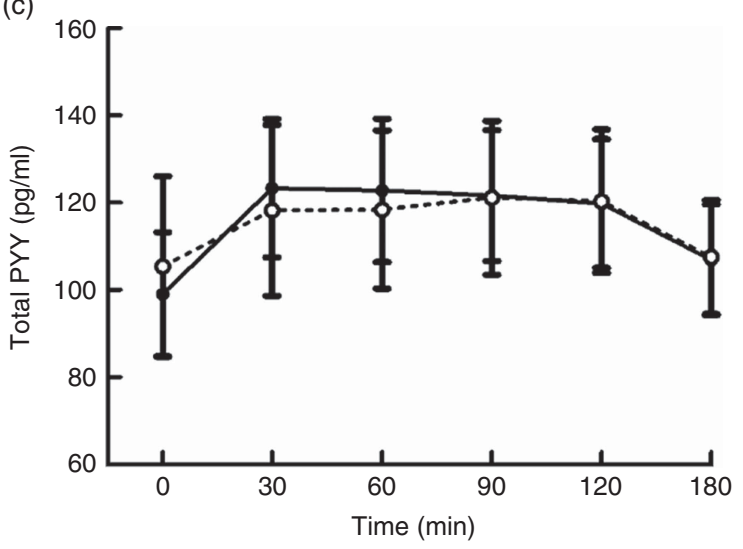

Fig. 2. Plasma acylated ghrelin (a), total glucagon-like peptide-1 (GLP-1) (b) and total peptide YY (PYY) (c) concentrations during a mixed-meal tolerance test after a day of supervised feeding in accordance with estimated energy requirements (energy balance trial; $\bullet$; solid line) or $50 \%$ overfeeding (overfeed trial; O; dashed line). Values are means $(n 12)$, with standard errors of the mean represented by vertical bars.

(two participants), the protein and fat content (one participant), the milk and water content (one participant) and one participant declined to guess the nature of the intervention.

\section{Discussion}

In the present study, we provide novel data demonstrating that $1 \mathrm{~d}$ of overfeeding $(+50 \% \mathrm{~kJ})$ with a balanced macronutrient profile does not elicit any compensatory changes in appetite perceptions, selected appetite-related hormone concentrations and ad libitum energy intake during an MTT the next day. In addition, although glucose and insulin responses were unaffected, $1 \mathrm{~d}$ of overfeeding elicited reduced plasma NEFA concentrations after an overnight fast and elevations in postprandial TAG concentrations during the MTT. These findings highlight the consequences of acute overfeeding as a stimulus for the accumulation of a positive energy balance and increased levels of TAG as a key CVD risk marker.

In addition to the absence of counter-regulatory appetite responses during the MTT, appetite perceptions also did not differ between trials during the day of energy intake manipulation (i.e. energy balance $v$. overfeeding). This observation contrasts with the established robust increases in appetite that occur during energy restriction ${ }^{(31-34)}$, even with modest deficits of $<800 \mathrm{~kJ}$ per meal ${ }^{(35)}$. Such divergent responses help to explain the ease of habitual overconsumption ${ }^{(6,8)}$ and the contrasting difficulties of sustained dieting ${ }^{(36)}$, especially in modern societies where energy-dense, highly palatable foods are abundant and easily accessible ${ }^{(2)}$. The gradual accumulation of a positive EB through repeated discrete episodes of overfeeding seems plausible, considering the absence of any compensatory appetite and energy intake responses during the MTT the next day. Indeed, mean values for both of these variables differed by $<2 \%$ between trials, which further highlight the limited physiological response to defend against excess energy intake ${ }^{(37)}$. These findings emphasise the need for conscious monitoring and adjustment of food intake around such episodes of overconsumption to prevent the gradual accumulation of a positive energy balance.

To understand the effects of overfeeding on physiological regulators of appetite control, circulating concentrations of selected appetite-related gastrointestinal hormones were measured during the MTT. In accordance with the findings discussed above, the overfeeding intervention did not stimulate any changes in fasted or postprandial concentrations of the orexigenic $^{(38)}$ hormone acylated ghrelin or the anorectic ${ }^{(38,39)}$ hormones PYY and GLP-1. These peptides represent key markers of impaired appetite regulation in obese individuals, as depressed concentrations of PYY and GLP-1 and reduced ghrelin responses to feeding are thought to be implicated in reduced satiety and hyperphagia ${ }^{(40-43)}$. The findings from the present study support previous evidence that 3-7d of overfeeding does not induce any changes in circulating ghrelin and GLP-1 concentrations ${ }^{(10,11,14)}$. Importantly, this also suggests that the assessments made after these longer interventions did not mask any immediate compensatory changes in hormone concentrations. Alternatively, Brøns et al. ${ }^{(14)}$ reported a borderline significant increase in fasted PYY concentrations after $5 \mathrm{~d}$ of high-fat overfeeding $(+50 \% \mathrm{~kJ}, 60 \% \mathrm{fat})$. Thus, it seems likely that more prolonged or high-fat overfeeding is required to induce compensatory changes in PYY concentrations, which accord with evidence that PYY release is more potently stimulated by fat than carbohydrate consumption ${ }^{(44)}$. Ultimately, the findings from the present study demonstrate that circulating concentrations of key appetite-related hormones do not change to provide a defence against an acute episode of 
(a)

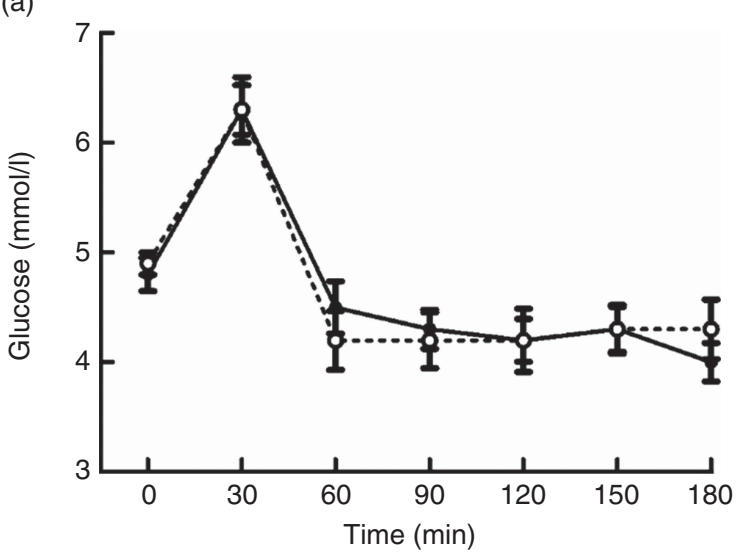

(c)

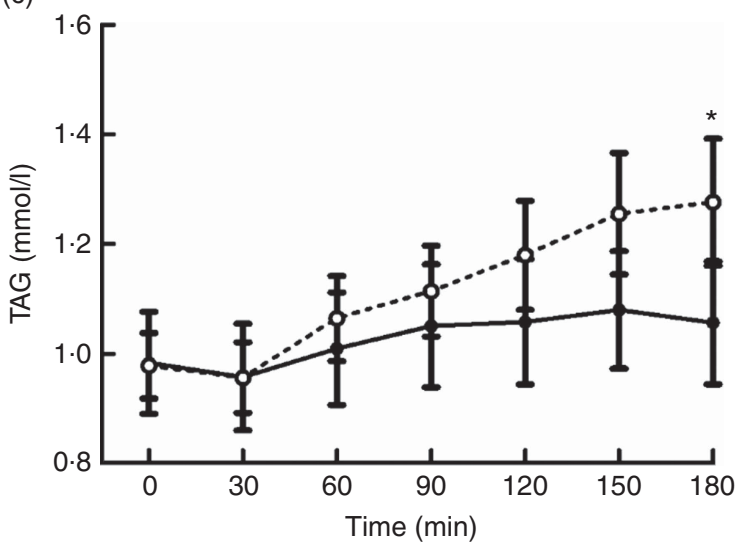

(b)

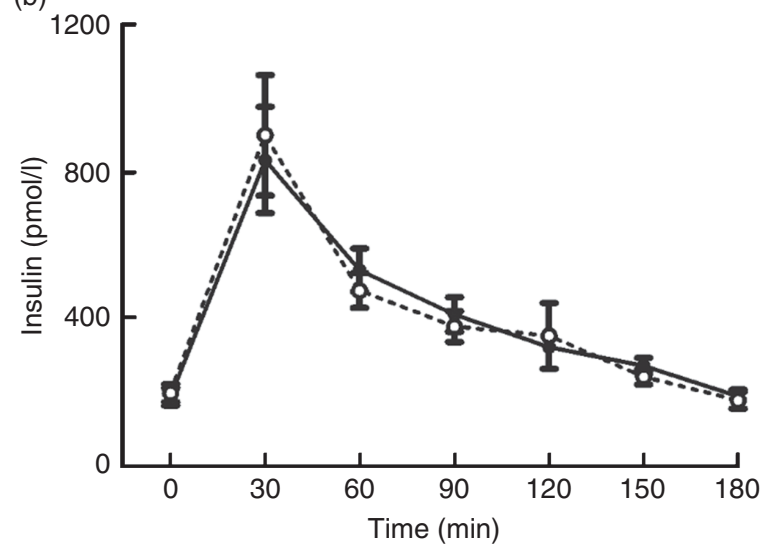

(d)

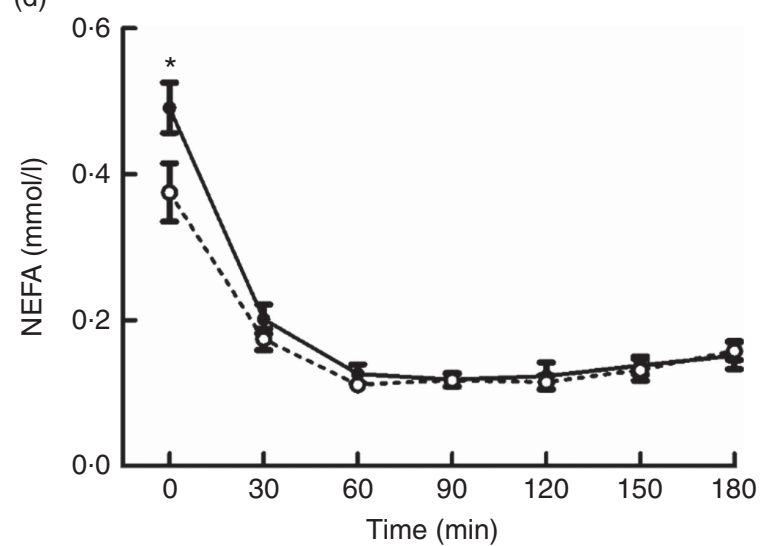

Fig. 3. Plasma glucose (a), insulin (b), TAG (c) and NEFA (d) concentrations during a mixed-meal tolerance test after a day of supervised feeding in accordance with estimated energy requirements (energy balance trial; 0 ; solid line) or $50 \%$ overfeeding (overfeed trial; O; dashed line). Values are means ( $n$ 12), with standard errors of the mean represented by vertical bars. ${ }^{*}$ Significant difference between trials determined via two-way ANOVA and post hoc paired $t$ test analysis of a significant trial $\times$ time interaction $(P<0.05)$.

overconsumption. The lack of change in these hormones also suggests that obesity-related dysfunctions in the appetiteregulating endocrine system do not occur acutely and are most likely stimulated by weight gain.

The focus of the present study on appetite, appetite-related hormones and energy intake responses precluded the additional measurement of energy expenditure during the MTT. Although this represents an important outcome to complete the energy balance equation, previous evidence suggests that massindependent increases in resting energy expenditure and dietinduced thermogenesis do not occur during chronic or shortterm overfeeding ${ }^{(13,45,46)}$. Differences in energy expenditure observed in response to energy intake manipulation appear to be the result of changes in light-intensity activity ${ }^{(47)}$, which was not permitted during the MTT in the present study. Lightintensity activities may also have been limited during the day of dietary manipulation based on the guidance to minimise physical activity levels. Nevertheless, it must be acknowledged that these activities often occur subconsciously ${ }^{(47)}$ and therefore that the lack of difference between trials during the day of dietary manipulation may represent a genuine absence in compensatory movement responses. Future investigations into the free-living responses to acute overfeeding would be beneficial to further investigate these effects.

The standardisation of physical activity levels during the first day of each trial was essential for the accurate assessment of appetite-related and metabolic responses to the intervention during the MTT. However, although energy expenditure was matched between trials, estimates from SenseWear armbands were approximately $1650 \mathrm{~kJ}$ higher than the predictive equations used to calculate the feeding interventions. The extent to which these values deviated from 'true' energy expenditures is unclear without the inclusion of a criterion measure in the present study, but a recently published meta-analysis suggests that SenseWear Pro3 armbands significantly overestimate energy expenditure during sedentary activities as performed during day 1 of each trial ${ }^{(48)}$. Regardless of these discrepancies in energy expenditure estimates, the use of predictive equations to prescribe energy intake is consistent with previous overfeeding interventions ${ }^{(10,14,17,23)}$ and is supported by the prescribed meals inducing an appropriate degree of satiation during the trials.

One day of overfeeding with a balanced macronutrient composition did not induce any changes in fasted or 
postprandial glucose and insulin concentrations during the MTT. This contrasts with the previously reported impairments in glycaemic control after high-fat overfeeding interventions $\left(+50 \% \mathrm{~kJ}, \geq 60 \%\right.$ fat) lasting for 5-7 $\mathrm{d}^{(10,14,16)}$, and more extreme high-fat overfeeding for a single day $(+78 \% \mathrm{~kJ}, 68 \% \text { fat })^{(17)}$. Although the shorter duration of moderate overfeeding in the present study may have reduced the stimulus for metabolic disturbance, these findings are also likely to reflect the impact of overfeeding with a balanced macronutrient composition. In this regard, recent evidence demonstrated that whole-body insulin sensitivity decreased after $3 \mathrm{~d}$ of high-fat overfeeding but increased after $3 \mathrm{~d}$ of high-carbohydrate overfeeding ${ }^{(18)}$. These differences appeared to be primarily mediated by changes in substrate oxidation at the muscle, which highlights the importance of divergent macronutrient intake for stimulating shortterm changes in glycaemic control.

Although markers of glycaemic control did not differ between trials, the overfeeding intervention induced significant elevations in postprandial TAG concentrations during the MTT. This is an important outcome, considering that postprandial lipaemia is an established independent risk factor for $\mathrm{CVD}^{(49,50)}$. Furthermore, the divergence in TAG concentrations between trials towards the end of the 180-min postprandial period suggests that this effect is likely to continue in response to subsequent feeding ${ }^{(51)}$. The mechanisms underlying the observed elevations in postprandial lipaemia are unclear but are likely to relate to the increased consumption of absolute amounts of carbohydrate and fat. In this regard, increased insulin release during high-carbohydrate overfeeding has been suggested to exaggerate postprandial lipaemia by increasing VLDL-TAG production and/or decreasing hydrolysis of circulating TAG due to reduced muscle lipoprotein lipase activity ${ }^{(18)}$. This potential role of elevated insulin concentrations during the day of dietary manipulation is also supported by the observed lower fasted concentrations of plasma NEFA after the day of overfeeding. Alternatively, increases observed after high-fat overfeeding have been suggested to be the result of increased storage and subsequent release of TAG within the enterocyte pool ${ }^{(17)}$. While further research is required to elucidate the mechanisms of this effect, these findings demonstrate that even short-term episodes of overfeeding with habitual macronutrient distributions can exert negative effects on metabolic control.

The present study has provided novel insights into the effects of an ecologically relevant episode of energy overconsumption on appetite-related and metabolic responses. Nevertheless, some limitations must be acknowledged. First, the blinding of participants to the overfeeding intervention may have prevented the occurrence of psychologically driven compensatory responses and subsequent reductions in energy intake during the MTT. Although this is feasible, the aim of this study was to isolate the physiological responses to excess energy consumption, which required the removal of potential psychological influences. The lack of counter-regulatory physiological changes in response to the overfeeding intervention highlights the ease with which energy overconsumption can occur, especially considering the increased prevalence of eating away from the home ${ }^{(52)}$ and limited awareness of required portion sizes more generally ${ }^{(53)}$. Second, although this is the first study to investigate the effects of
$1 \mathrm{~d}$ of mixed-macronutrient overfeeding, these findings must be extended to investigate the consequences of repeated bouts of such overconsumption. Evidence from chronic overfeeding interventions suggests that additional compensatory responses are unlikely to occur with repeated exposure ${ }^{(46)}$, but future investigations remain essential to confirm the role of repeated discrete episodes of overconsumption in the accumulation of a positive energy balance. Third, the consequences of dietary practices for potential weight gain and metabolic impairments in presently healthy young men were investigated. However, although the prevention of weight gain has been highlighted as a major public health priority ${ }^{(54)}$, these findings may not generalise to women or obese participants. Future investigations in these populations would be beneficial, especially in obese participants to further understand the effects of dietary manipulation on energy balance and weight control.

In conclusion, this study demonstrated that $1 \mathrm{~d}$ of overfeeding with a balanced macronutrient profile does not elicit any compensatory changes in appetite perceptions, selected appetite-related hormone concentrations and ad libitum energy intake during an MTT the next day. Appetite perceptions during the day of overfeeding were also unaffected. Taken together, this absence of compensatory appetite-related responses to an ecologically relevant overfeeding protocol supports the concept that repeated discrete episodes of overconsumption may promote weight gain. Increases in postprandial TAG concentrations during the day after overfeeding further emphasise the risks of acute dietary excess. These findings highlight the need for dietary awareness and conscious compensatory behavioural adjustments should episodes of overconsumption occur.

\section{Acknowledgements}

The authors thank all of the volunteers for their participation in this study. The authors also thank James Taylor and Emma Kellett for their help with data collection.

This research received no specific grant from any funding agency, commercial or not-for-profit sectors.

K. D. and A. H. conceived the study; K. D., A. J. K., J. M., O. M. S. and A. H. designed the study; all authors contributed to data collection, analysis and interpretation; K. D. drafted the manuscript; all authors revised and approved the final version of the manuscript.

The authors declare that there are no conflicts of interest.

\section{Supplementary material}

For supplementary material/s referred to in this article, please visit https://doi.org/10.1017/S0007114519000205

\section{References}

1. Seidell JC \& Halberstadt J (2015) The global burden of obesity and the challenges of prevention. Ann Nutr Metab 66, 7-12.

2. Swinburn BA, Sacks G, Hall KD, et al. (2011) The global obesity pandemic: shaped by global drivers and local environments. Lancet 378, 804-814. 
3. Wing RR \& Phelan S (2005) Long-term weight loss maintenance. Am J Clin Nutr 82, 222S-225S.

4. Greenway FL (2015) Physiological adaptations to weight loss and factors favouring weight regain. Int J Obes 39, 1188-1196.

5. Østbye T, Malhotra R \& Landerman LR (2011) Body mass trajectories through adulthood: results from the National Longitudinal Survey of Youth 1979 cohort (1981-2006). Int J Epidemiol 40, 240-250.

6. Yanovski JA, Yanovski SZ, Sovik KN, et al. (2000) A prospective study of holiday weight gain. $N$ Engl J Med 342 , 861-867.

7. Casazza K, Fontaine KR, Astrup A, et al. (2013) Myths, presumptions, and facts about obesity. $N$ Engl J Med 368, 446-454.

8. Racette SB, Weiss EP, Schechtman KB, et al. (2008) Influence of weekend lifestyle patterns on body weight. Obesity $\mathbf{1 6}$, 1826-1830.

9. Schoeller DA (2009) The energy balance equation: looking back and looking forward are two very different views. Nutr Rev 67, 249-254.

10. Parry SA, Smith JR, Corbett TRB, et al. (2017) Short-term, highfat overfeeding impairs glycaemic control but does not alter gut hormone responses to a mixed meal tolerance test in healthy, normal-weight individuals. Br J Nutr 117, 48-55.

11. Hagobian TA, Sharoff CG \& Braun B (2008) Effects of shortterm exercise and energy surplus on hormones related to regulation of energy balance. Metabolism 57, 393-398.

12. Chin-Chance C, Polonsky KS \& Schoeller DA (2000) Twentyfour-hour leptin levels respond to cumulative short-term energy imbalance and predict subsequent intake. $J$ Clin Endocrinol Metab 85, 2685-2691.

13. Dirlewanger M, Di Vetta V, Guenat E, et al. (2000) Effects of short-term carbohydrate or fat overfeeding on energy expenditure and plasma leptin concentrations in healthy female subjects. Int J Obes 24, 1413-1418.

14. Brøns C, Jensen CB, Storgaard H, et al. (2009) Impact of shortterm high-fat feeding on glucose and insulin metabolism in young healthy men. J Physiol 587, 2387-2397.

15. Kolaczynski JW, Ohannesian JP, Considine RV, et al. (1996) Response of leptin to short-term and prolonged overfeeding in humans. J Clin Endocrinol Metab 81, 4162-4165.

16. Hulston CJ, Churnside AA \& Venables MC (2015) Probiotic supplementation prevents high-fat, overfeeding-induced insulin resistance in human subjects. Br J Nutr 113, 596-602.

17. Parry SA, Woods RM, Hodson L, et al. (2017) A single day of excessive dietary fat intake reduces whole-body insulin sensitivity: the metabolic consequence of binge eating. Nutrients 9, E818.

18. Lundsgaard AM, Sjøberg KA, Høeg LD, et al. (2017) Opposite regulation of insulin sensitivity by dietary lipid $v$. carbohydrate excess. Diabetes 66, 2583-2595.

19. Rousset S, Fardet A, Lacomme P, et al. (2015) Comparison of total energy expenditure assessed by two devices in controlled and free-living conditions. Eur J Sport Sci 15, 391-399.

20. Travers RL, Motta AC, Betts JA, et al. (2017) Adipose tissue metabolic and inflammatory responses to a mixed meal in lean, overweight and obese men. Eur J Nutr 56, 375-385.

21. Selimoglu H, Duran C, Kiyici S, et al. (2009) Comparison of composite whole body insulin sensitivity index derived from mixed meal test and oral glucose tolerance test in insulin resistant obese subjects. Endocrine 36, 299-304.

22. Mifflin MD St, Jeor ST, Hill LA, et al. (1990) A new predictive equation for resting energy expenditure in healthy individuals. Am J Clin Nutr 51, 241-247.

23. Votruba SB, Kirchner H, Tschöp M, et al. (2009) Morning ghrelin concentrations are not affected by short-term overfeeding and do not predict ad libitum food intake in humans. Am J Clin Nutr 89, 801-806.

24. Dhurandhar NV, Schoeller D, Brown AW, et al. (2015) Energy balance measurement: when something is not better than nothing. Int J Obes 39, 1109-1113.

25. Public Health England. Government Dietary Recommendations (2016) https://assets.publishing.service.gov.uk/government/ uploads/system/uploads/attachment_data/file/618167/govern ment_dietary_recommendations.pdf (accessed June 2018).

26. Flint A, Raben A, Blundell JE, et al. (2000) Reproducibility, power and validity of visual analogue scales in assessment of appetite sensations in single test meal studies. Int J Obes Relat Metab Disord 24, 38-48.

27. Stubbs RJ, Hughes DA, Johnstone AM, et al. (2000) The use of visual analogue scales to assess motivation to eat in human subjects: a review of their reliability and validity with an evaluation of new hand-held computerized systems for temporal tracking of appetite ratings. Br J Nutr 84, 405-415.

28. Deighton K, Frampton J \& Gonzalez JT (2016) Test-meal palatability is associated with overconsumption but better represents preceding changes in appetite in non-obese males. Br J Nutr 116, 935-943.

29. Hosoda H, Doi K, Nagaya N, et al. (2004) Optimum collection and storage conditions for ghrelin measurements: octanoyl modification of ghrelin is rapidly hydrolyzed to desacyl ghrelin in blood samples. Clin Chem 50, 1077-1080.

30. Faul F, Erdfelder E, Lang AG, et al. (2007) G*Power 3: a flexible statistical power analysis program for the social, behavioral, and biomedical sciences. Behav Res Methods 39, 175-191.

31. King JA, Wasse LK, Ewens J, et al. (2011) Differential acylated ghrelin, peptide YY3-36, appetite, and food intake responses to equivalent energy deficits created by exercise and food restriction. J Clin Endocrinol Metab 96, 1114-1121.

32. Hubert P, King NA \& Blundell JE (1998) Uncoupling the effects of energy expenditure and energy intake: appetite response to short-term energy deficit induced by meal omission and physical activity. Appetite 31, 9-19.

33. Clayton DJ, Creese M, Skidmore N, et al. (2016) No effect of $24 \mathrm{~h}$ severe energy restriction on appetite regulation and ad libitum energy intake in overweight and obese males. Int $J$ Obes 40, 1662-1670.

34. Thivel D, Finlayson G, Miguet M, et al. (2018) Energy depletion by 24-h fast leads to compensatory appetite responses compared with matched energy depletion by exercise in healthy young males. Br J Nutr 120, 583-592.

35. Deighton K, Batterham RL \& Stensel DJ (2014) Appetite and gut peptide responses to exercise and calorie restriction: the effect of modest energy deficits. Appetite 81, 52-59.

36. Ikeda JP, Lyons P, Schwartzman F, et al. (2004) Self-reported dieting experiences of women with body mass indexes of 30 or more. J Am Diet Assoc 104, 972-974.

37. Schwartz MW, Woods SC, Seeley RJ, et al. (2003) Is the energy homeostasis system inherently biased toward weight gain? Diabetes 52, 232-238.

38. Karra E \& Batterham RL (2010) The role of gut hormones in the regulation of body weight and energy homeostasis. Mol Cell Endocrinol 316, 120-128.

39. Murphy KG \& Bloom SR (2006) Gut hormones and the regulation of energy homeostasis. Nature 444, 854-859.

40. le Roux CW, Patterson M, Vincent RP, et al. (2005) Postprandial plasma ghrelin is suppressed proportional to meal calorie content in normal-weight but not obese subjects. J Clin Endocrinol Metab 90, 1068-1071. 
41. le Roux CW, Batterham RL, Aylwin SJB, et al. (2006) Attenuated peptide YY release in obese subjects is associated with reduced satiety. Endocrinology 147, 3-8.

42. Verdich C, Toubro S, Buemann B, et al. (2001) The role of postprandial releases of insulin and incretin hormones in meal-induced satiety - effect of obesity and weight reduction. Int J Obes 25, 1206-1214.

43. Hussein MS, Abushady MM, Refaat S, et al. (2014) Plasma level of glucagon-like peptide 1 in obese Egyptians with normal and impaired glucose tolerance. Arch Med Res 45, 58-62.

44. Essah PA, Levy JR, Sistrun SN, et al. (2007) Effect of macronutrient composition on postprandial peptide YY levels. J Clin Endocrinol Metab 92, 4052-4055.

45. Müller MJ, Enderle J \& Bosy-Westphal A (2016) Changes in energy expenditure with weight gain and weight loss in humans. Curr Obes Rep 5, 413-423.

46. Siervo M, Fruhbeck G, Dixon A, et al. (2007) Efficiency of autoregulatory homeostatic responses to imposed caloric excess in lean men. AJP Endocrinol Metab 294, E416-E424.

47. Betts JA, Richardson JD, Chowdhury EA, et al. (2014) The causal role of breakfast in energy balance and health: a randomized controlled trial in lean adults. Am J Clin Nutr 100, 539-547.
48. O'Driscoll R, Turicchi J, Beaulieu K, et al. (2018) How well do activity monitors estimate energy expenditure? A systematic review and meta-analysis of the validity of current technologies. Br J Sports Med (Epublication ahead of print version 7 September 2018).

49. Bansal S, Buring JE, Rifai N, et al. (2007) Fasting compared with nonfasting triglycerides and risk of cardiovascular events in women. JAMA 298, 309-316.

50. Nordestgaard BG, Benn M, Schnohr P, et al. (2007) Nonfasting triglycerides and risk of myocardial infarction, ischemic heart disease, and death in men and women. JAMA 298, 299-308.

51. Arjunan SP, Deighton K, Bishop NC, et al. (2015) The effect of prior walking on coronary heart disease risk markers in South Asian and European men. Eur J Appl Physiol 115, 2641-2651.

52. Adams J, Goffe L, Brown T, et al. (2015) Frequency and sociodemographic correlates of eating meals out and take-away meals at home: cross-sectional analysis of the UK national diet and nutrition survey, waves 1-4 (2008-12). Int J Behav Nutr Phys Act 12, 51.

53. Roberto CA \& Khandpur N (2014) Improving the design of nutrition labels to promote healthier food choices and reasonable portion sizes. Int J Obes 38, S25-S33.

54. Lawlor DA \& Chaturvedi N (2006) Treatment and prevention of obesity - are there critical periods for intervention? Int J Epidemiol 35, 3-9. 